\title{
Meri Uuno Kailaan runoudessa
}

Uuno Kailaan runouden tulkitsijat ovat miltei yksimielisesti tulleet siihen tulokseen, että Kailas ei varsinaisesti ollut luonnonrunoilija ja että häneltä jopa varsin suuressa määrin puuttui luonnontaju.1 Elämäkerran kirjoittaja, tohtori Niinistö, toteaa sitä paitsi, että meri ei Kailaan runoudessa ole mitenkään keskeinen symboli.2 Mitä tulee nimenomaan luonnontunteen ilmenemiseen Kailaan lyriikassa, on tutkijoiden löytämä aines siinä suhteessa todellakin niukka. Se elävä, luonnonläheinen floora ja fauna, joka monelle lyyrikolle on merkinnyt suoranaista luomisroiman ehtoa, on Uuno Kailaan jättänyt melkein kokonaan välinpitämättömäksi. Kuitenkin täytynee olettaa, että elämyspohja ei saattanut jäädä hänelle vieraaksi. Runoilija joutui maaseudun lapsena jo varhain lähelle luontoa, joskin kotiseutu oli kasvullisuudeltaan köyhää ja jylhän erakkomaiseman kaltaista. ${ }^{3}$ Uuno Kailaan runoissa ovat kuitenkin ylen harvinaisia kukat, puut, linnut ja muut tutut maiseman yksityiskohdat. Näihin puuttuviin maisemakuvauksiin voidaan vielä liittää sisämaan rikkaat vesistöt. Tätä taustaa vasten kannattaa sitäkin suuremmalla syyllä kiinnittää huomiota hänen lukuisiin merikuvitelmiinsa. Itse asiassa elämäkerran kirjoittaja on oikeassa siinä, että kiinteästi kiteytettyjä merimaisemia ja luonnontunteen läpäisemiä merellisiä kuvia on Kailaan runoudessa verraten vähän. Mutta meri esiintyy Kailaalla joka tapauksessa harvinaisen usein eri yhteyksissä, ja eritoten sen merkitys vertauskuvallisesti on useinkin syvällinen ja hänen persoonallisuuttaan valaiseva.

1 Tatu Vaaskivi, Muudan runoilijakuva. Suomalainen Suomi 1947. S. 405. Unto Kupiainen, Suomalainen lyriikka Siljosta Sarkiaan. Porvoo 1948. S. 213.

2 Maunu Niinistö, Uuno Kailas. Hänen elämänsä ja hänen runoutensa. Porvoo 1956. S. 345.

3 Maunu Niinistö, emt. s. 24. 
Koska Hämeen ja Savon rajamaiden erämaapitäjässä Hartolassa lapsella ei ollut mitään mahdollisuutta muodostaa mielikuvaa aavasta ja rannattomasta merestä, täytyy olettaa, että runoilijan vaikutelmat merellisistä maisemista ovat olleet ensi sijassa kirjallisia. Maunu Niinistö mainitsee tulevan runoilijan jo koulussa olleen erikoisen kiinnostuneen maantieteestä, jonka avulla hän pääsi riistäytymään arkipäivän yksitoikkoisesta kotipiiristä kaukaisiin, kiehtoviin maihin. Tämä ei tietenkään vielä sinänsä riitä selittämään epätavallista kiinnostusta mereen, koska pidetään pikemminkin sääntönä kuin poikkeuksena sitä, että jokaisen kansakouluikäisen poikasen haveena on merenkyntäjän ammatti. Loma-aikoinaan koulupoika Kailas joka tapauksessa rakenteli monikerroksisia ja ihmeellisiä laivoja, joita hän kävi uittamassa riihen takaisessa lammessa. Niiden etäinen matkan määränpääkin oli mielikuvitusta herättävän kaukainen: Port Said (!)4 Opiskelukaupungissa meri muuttui maantieteellisesti läheisemmäksi, mutta luultavaa on, että merelliset kuvat Kailaan runoudessa on loppuun asti katsottava kirjallisiksi lainoiksi.

Kootessaan viimeisenä kirjallisena tehtävänään elämäntyönsä tuloksia runovalikoimaansa Kailas osoitti aivan erikoista kriitillisyyttä. ${ }^{5}$ Hän kelpuutti viiden kokoelmansa yli kahdestasadasta runosta lopulliseen valikoimaan vain puolet. Tavalla tai toisella merisymboliikan ympärille ryhmittyneet runot ovat tässä seulonnassa kärsineet prosenttimääräisesti yhtä suuren tappion. Kailaan itsekritiikki ei siis ole merellisten kuvien kohdalla lopullisessakaan valinnassa poikennut hänen sille asettamistaan vaatimuksista. Syyn voi tietysti löytää toisaaltakin: Kailaan suhde mereen on säilynyt jotensakin samanlaisena aina viimeiseen valintaan asti. Eniten on merirunoja päässyt mukaan kokoelmasta Purjehtijat, joka jo nimensäkin puolesta tunnustautuu merellisten aiheiden kannattamaksi ja jossa merirunoja onkin runsaammin kuin missään muussa Kailaan runokokoelmassa.

Kun lähdetään tarkastelemaan niitä kirjallisten lainojen mahdollisuuksia, jotka voivat tulla kysymykseen lähteinä Kailaan merirunoudessa, tulee tietysti mieleen yhtenä henkisenä oppi-isänä Char-

4 Maunu Niinistö, emt. s. 54.

5 Aaro Hellaakoski, Kailaan itsekritiikistä, Kuuntelua, Essseitä teoksista ja tekijöistäa, Pợvoọ 1950, S, 212, 
les Baudelaire, jonka läheinen kosketus Kailaan runouteen on jo todettu. ${ }^{6}$ Baudelairen pitkällä merimatkallaan saamat kokemukset on talletettu hänen moniin runoihinsa.7 Kailaan Silmästä silmäänkokoelman neljästä Baudelairen-suomennoksesta on kolmessa merellisiä kuvia, näitten runojen joukossa kuuluisaksi tullut "Albatross". Muista lyyrikoista, joitten runouden koulua Kailas on käynyt jo koulupoikanạ, elämäkerran tekijä mainitsee erikoisesti Koskenniemen ja Leinon. 8 Kailaan merirunotkin ovat voineet saada lähtökohtia näiden runoilijoiden tuotannosta. On vaikea tehdä kiistattomia johtopäätöksiä, mutta ainakin läheisiä yhtymäkohtia voidaan mainita. Koskenniemen runossa "Mister Hartley" ja Kailaan "Purjehtijoissa" on molemmissa toivoton tilanne syvyyksien päällä: me vajoamme. Kailaan runo erkanee aavelaivamotiivin kautta syvään itsetutkisteluun - nimenomaan syvyys on kohta, johon on syytä myöhemmin palata - kun taas Koskenniemi antaa runossaan kuolemanajatuksen päättyä ylevään resignaatioon. Koskenniemen runossa "Ovidius Tomissa" on edelleen sama vangitun sielun kaipaus kuin Kailaan "Kalypson vangissa". Kailaalla esiintyy usein tähtikirkas yöllinen meri, Koskenniemellä se on erikoisen vaikuttava runoissa "Iltalaulu merellä" ja "öinen meri". Niinistö on viitannut Kailaan runon "Laulu aallolle" yhteydessä Koskenniemen "Hyökyaaltoon".9 Leinon "Tku-Turso" tulee etsimättä mieleen, kun lukee Kailaan "Verkossa"-runon säkeitä. Vangitun sielun kaipaus kuvastuu yhtä tuskallisena kummassakin, Leinolla tosin verrattomasti rajumpana ja uhmaavampana. Kailaalla kahlittu on "verkon silmässä kala", joka ei voi tavoittaa "vapaita vesiä", vaikka hänen halunsa kurkottuukin niihin. Verkon silmukat yhä vain kiristyvät. Leinon Iku-Turso on mahtava, uhmaava ja jumalia kiihkeästi vihaava hengen jättiläinen, mutta meri on hänellekin takonut kahleet: "Ma vapautta pyydän, / ma valkeutta janoon, / ja kauneutta taivahan kaarten ma palan, / mut pääse en kahleista vaikean vai-

6 V. A. Koskenniemi, Kaksi runoilijakutsumusta. Runousoppia ja runoilijoita. Porvoo 1951. S. 222. Lauri Viljanen, Uuno Kailaan uudet runot. Helsingin Sanomat 14.11. 1926. Unto Kupiainen, emt. s. 231.

7 Eino Palola, Brontesta Lagerlöfiin. Maailmankirjallisuuden suurimpien mestarien elämäkertoja. Porvoo 1950. S. 112.

s Maunu Niinistö, emt. s. 69.

9 Maunụ Niinistö, emt. s, 234, 
van, / voin pään nostaa, / muu muran peittoon muotoni jää." Verkon silmukkaan kytketty kala on alistuneempi, pikemminkin kiduttavan kuoleman kourissa vaikertava kärsijä kuin uhmaaja, mutta kaipaus vapauteen on yhtä kiihkeä: "Mikä autuus ois lohen kilpaveikkona olla!"

Ei liene kovin kaukana oikeasta myöskään se olettamus, että näihin kirjallisiin esikuviin Kailaan merirunoudessa on liitettävä lapsuudenaikaiset muistot Raamatun antamasta maailmankuvasta. Maunu Niinistö tietää tulevan runoilijan ensimmäisiä lukuharrastuksia syvästi uskonnollisessa kasvatuskodissa olleen Raamatun, jonka maailmankuvan hänelle oli välittänyt isoäiti jo ennenkuin poika osasi lukeakaan.10 Ei ole vaikea kuvitella, miten valtavan vaikutuksen pieneen poikaan on tehnyt Mooseksen kirjan alku: "Ja maa oli autio ja tyhjä, ja pimeys oli syvyyden päällä, ja Jumalan henki liikkui vetten päällä. Ja Jumala sanoi: 'Tulkoon valkeus', ja valkeus tuli." Tämä Raamatun kohta on melkein samoin sanoin kuvattu Silmästä silmään-kokoelman runossa "Luominen", jonka runoilija omisti Jean Sibeliukselle tämän 60-vuotispäivänä:

Yhä luominen jatkuu. Ja syvien vetten päällä yhä Henki käy. Ja hän samoo pimeään.

Syvä, autio tyhjyys niinkuin nukkuja herää hänen henkäyksestänsä elämään.

Kailaan merikuviin liittyy kautta koko hänen tuotantonsa ääretön, määrätön syvyys. Meren ulottuvuus on useissa hänen runoissaan kiehtovampi alaspäin kuin lavealle taivaanrantaan päin. "Intialaisessa kuvitelmassa" "Naryana kääntyi ja katseli syviin vesiin", "Adagiossa" on "hetki rajaton kuin meren sydän salainen ja syvä". "Purjehtijoissa" "on syvyys allamme kuin lohikäärmeen suu". "Verkossa" on "vesi päilyvä, selvä ja syvä". "Hollantilaisessa" on syvyysvaikutus niin ikään hyvin puhuva. "Katseen" meressä on "toivottomia syvyyksiä". "Atlantis"-runossa saari vaipuu meren syvyyteen. Runo "Sana" on suoraan Raamatun luomiskertomuksen pohjalta syntynyt, ja se sulkee sisäänsä maan, meren ja koko taivaanpiirin laajentuen lopussa runoilijan luomistyön symboliksi.

Merenpohjan elävään tulkintaan ja sen yksityiskohtaiseen kuvaukseen ei Kailas vielä saanut tukea Raamatun kertomuksista.

10 Maunu Niinistö, emt. s. $43-44$. 
Mooseksen ensimmäinen kirja mainitsee vain, että "Jumala loi suuret merieläimet, ja kaikkinaiset liikkuvaiset eläimet, joita vedet kuohuttivat yltäkyllä, kunkin lainsa jälkeen", mutta se värikäs eläin- ja kasvimaailma, joka aukenee silmiemme eteen myöhemmän ajan kirjallisuudessa, on myöhempien tutkimusten tulos. Rinnan uudemman lyriikan syntyessä viime vuosisadalla saatiin tarkempi selko myös meren pohjasta luonnontieteellisten tutkimusten ansiosta. Ne antoivat uutta sisältöä ja eloa vanhoille käsityksille veden asemasta maapallolla. Syvänmeren tutkimuksen historia alkaa vasta 1800-luvun alkupuolella, ja se liittyi kauan läheisesti siihen kysymykseen, onko valtameren syvyyksissä elämää. Löytöretket auttoivat tiedemiehiä muodostamaan entistä tarkemman kuvan merestä ja sen laadusta, erikoisesti sen eläin- ja kasvimaailmasta. Suorastaan mullistavasti maailmankuvan selvenemiseen vaikuttivat tulokselliset syväluotaukset, joita suoritettiin erikoisen innokkaasti 1800-luvun lopulla. Nämä tutkimukset muuttivat kerrassaan ratkaisevasti käsitykset meren syvyydestä, joka vielä viime vuosisadan alkupuolella käsitettiin tyhjiöksi ilman orgaanista elämää. Päivänvaloon saatettiin nyt harvinaisia, primitiivisiä eläin- ja kasvimuotoja, jotka saivat biologit siirtymään hyvän askeleen kehitysoppia kohden. Ne olivat tutkimuksia, jotka olivat yhtä kiehtovia tieteelliselle ajattelulle kuin esteettiselle mielikuvitukselle.11

Uuno Kailaan runous on jo kotiutunut tähän uuteen ajatustapaan. Meri on hänelle elävä olento, joka pohjaan asti liikkuu ja hengittää elävän olennon tavoin. Runoilija puhuu meren sydämestä ja meren sielusta. Merellä on vihreät silmät ja sen katseessa on rannattomuus. Syvällä pinnan alla on oma salaperäinen maailmansa. Se liikehtii ja värähtelee aaltojen alla vihreänkimalteisena ja viekoittelevana. Varsinkin pintavedet ovat Kailaalle liikkuvia, matkaa tekeviä. "Elämän ylistyksessä" ihminen, jota ei elämän väkevä tulva tempaa mukaansa matkalle ikuiseen mereen, on vain seisovaa vettä, ja hän mätänee. Runossa "Laulu aallolle" meren ja aaltojen liike kiihtyy karkeloivaksi, läikkyväksi ja kuplivaksi. Kuohuvat pintavedet vaihtuvat rauhallisemmiksi, mitä syvemmälle mennään pinnan alle. Runossa "Hauta meren alla" Jim laskeutuu

11 Alf Kjellén, Diktaren och havet. Drift- och drömsymbolik i svenskspråkig lyrik 1880-1940, Stockholm 1957. S. 19. 
"aaltoihin vyöryviin", mutta tapaa syvällä vedessä omituisen kelmeän, liikkumattoman elollisuuden. Meren pohjalla on hiljaa huokuva, mietiskelevä äänettömyys.

Elävää, vapauttavaa, vyöryvää läikyntää ei Kailas liitä muihin vesimaisemiinsa. Rannan tuntumassa on vesi rutaista ("Ilta"), lammen pinta on sammalkaihin peittämä ("Noli me tangere"). Lähteen vesi on seisovaa. Sen syvyyden kalvo on liikahtamaton, kuvastimen kaltainen, kova ja sileä ("Kuva"). Virta on Kailaalle kuoleman tumma virta, joka kuljettaa vainajia ("Suru").

Kailaan syvänmeren kuvitelmiin liittyy joskus hyvinkin läheisesti sadunomaisia mielikuvia. "Hollantilaisessa" "näit edessäsi unet kultaiset / kuin tornit, uponneina aallon alle". Kailas on Lentävän hollantilaisen tarinassa nähnyt erään kimaltelevista näyistään, kutsumustietoisuudessaan kamppailevan runoilijan pyrkimyksen kohti ikuista kauneutta. Se on kaukana Hellaakosken aavelaivurin uhmasta, ja siinä kuvastuu kärsimys ja toivottomuus: 'Et aavain kimallusta vanginnut." Toivottomalta vaikuttava pyrkiminen meren salaisuutta kohti ei kuitenkaan lannista unten kalastajaa:

- Mut yhä edessäsi kimmeltäin on merta, kaupunkeja aallon alla. Käy kätes ruoriin : keula niitä päin! Taas sata vuotta kuljet ulapalla.

Runossa on niin vahvasti unen- ja sadunomainen maisema, että Niinistö toteaakin runoilijan olevan tässä ulapankulkija kohtalonomaisessa mielessä. Hänen merensä ei ole luonnonkuva vaan fantasian erämaa, symbolinen vaellustie. ${ }^{12}$ Tätä fantasianomaisuutta korostaa sekin, että meri kuultaa merenkulkijan silmiin yöllä aivan toisennäköisenä kuin päivällä. "öin ylläs, allas tähtiparvi on", mutta päivisin se on "kuolleen-harmaa, tyhjän toivoton". Unen ja sadun välimailla väreilee myös "Atlantis"-runon merellinen maisema. Tässäkin runossa lyyrikko on muokannut vanhan satuaiheen unen ja kuoleman rakastajan sielunliikkeitä vastaavaksi. Onnellisten saari, josta tulee merenpohjainen peikkojen luola, on jyrkkä antiteesi, josta Kailaan dualismi selkeästi kuvastuu.

12 Maunu Niinistö, emt. s 348. 
Kailaan merikuvien koristeellisuus on myös ekspressionistien suosiman värikylläisyyden ilmennystä. 13 Ekspressionistista kuvaromantiikkaa on suorastaan kasattu Purjehtijat-kokoelman "Intialaiseen kuvitelmaan", jossa koristeellisuudelle on uhrattu luonnontieteelliset tosiasiatkin. Naryana, kaunis ruskea jumala, lepää vienosti läikehtivässä meressä lumpeenlehdellä lähellä taivaan seinää. Hän rakastaa meren tytärtä niin rajusti, että meressä nousee myrsky, ja aallot heittävät helmiä taivaan kattoon. Runossa on sateenkaaren välkettä ja kultakalojen kimallusta. Meren ja lumpeenkukat runoilija yhdistää niin ikään myös "Katseessa", jossa ihmisen silmistä kuvastuu sielumeri, syvä ja salattu, arvoituksellinen ja kirkas samalla kertaa.

Merenpohjan elävyyttä korostavat Kaiłaalla levät, jotka hiljaa huojuen tuovat pinnanalaiseen maailmaan omituista, häilyvää elollisuutta. Runossa "Hauta meren alla" sukeltaja laskeutuu alas syvyyteen:

Yli yhdeksänkymmentä jalkaa näin hän oli jo alla veen,

kun lyhdyn valossa himmeän

sai nähdä hän viimeinkin

merenpohjan allansa häämöittävän

levin hiljaa huojuvin.

Pian sille jalkansa laski hän

liki loistavan maneetin.

Meren eläinmaailma on Kailaalla verraten köyhää, kalojakin esiintyy tuiki harvoin. Sen vuoksi kannattaa panna merkille, että hän tässä runossa sijoittaa sinne nimenomaan "loistavan" maneetin. Ei ole tietoa, minkä verran Kailas tunsi tätä onteloeläinten sukua, mutta luultavinta on, että sanan tarkoituksena on tuoda runoon voimakasta eksoottista värikkyyttä. Tässäkin runossa, jossa kertovan juoniaineksen ohella meren asema on keskeinen, on huomattava, että Kailas harvoin haluaa merta kuvaamalla virittää yksinomaisesti luonnontunnelmaa. Runossa on syvä sielullinen pohja-ajatus. Kun runohenkilö Jim tapaa hukkuneesta laivasta kuolevan toverinsa, joka kohtalokkaalla tavalla on katkeroittanut hänen elämäänsä,

13 Unto Kupiainen, emt. s. 222. 
antaa meren syvyys järkyttävää taustaväriä niihin kuiluihin, joita on myös ihmissielun syvyyksissä. Kun Jim kuulee kuolemanlaivan asukkaan heikolla äänellä tekevän tunnustuksensa, kouraisee se syvältä hänenkin sieluunsa:

Jim läähätti. Tutkain puraissut

oli suoraan sydämeen.

Meren kuilussa kuilu auennut

oli syvemmä syvyyteen.

Meri kuvastaa yleensäkin ilmeisen selvästi Kailaan lyyrikonluonteen henkisiä Januksen-kasvoja. Se on toisaalta avara vapauden symboli, jolta kuitenkin koristeellinen kuva-aines riistää jylhän monumentaalisen jykevyyden, toisaalta se on alas syvimpiin syvyyksiin porautuvaa, ihmissielun salaisten pohjamutien tutkistelua. Mutta myöskin taivaanrantaan avartuva meri on joskus vangitseva ja kauhua herättävä. "Kalypson vangissa" "janoni vihaa sinua, vaikka en voi olla sinua rakastamatta". Meri ilkkuu jumalattaren vankia, joka haluaisi paeta tämän rakkautta ja kuolemattomuutta. Koskenniemen Ovidiuksen tavoin mies tähyilee yli meren kotirantaa päin ja seuraa kaipaavin katsein pilviä, jotka kiitävät vapaasti minne mielivät, ja aaltoja, jotka välkkyvin evin ja pärskyvin pyrstöin huimina ja vapaina kiitävät kauas.

Kailaan merikuviin liittyy erikoisen oleellisena taivas. Korkeus ja syvyys, kiehtovan voimakas antiteesi, on hänen monissa merirunoissaan saanut juhlallisen ja monumentaalisen ilmaisun. Raamatun luomiskertomuksen tunnelmaa on - kuten jo aikaisemmin mainittiin - runossa "Luominen". Linnunrata piirtyy komeana kaarena taivaalle ja mestarin käsistä sinkoutuu aurinkoja. Niin ikään "Punajuovassa", jonka Kailas ihaillen omisti Eino Leinolle, "punajuova jäi ylös otsalle taivaan", mutta korvenhaltija on jatkanut matkaansa "päin sinimerta". "Intialaisessa kuvitelmassa" Naryana poimii tähtiä taivaalta ja pudottelee niitä mereen. Tähtien vajoaminen meren pohjaan, jossa ne loistavat kuin Meren tyttären silmät, on ihmeen kaunis yöllinen runokuva. Nimenomaan meri yöllä saa Kailaalla usein loistavia ja kimaltelevia muotoja. "Purjehtijoissa" kuvastuu kuu taivaalta mereen. Se on kuin paholaisen silmä syvyyden päällä kulkevien merimiesten mielestä. Taivaan kaaren huikaiseva korkeus ja meren pohjaton syvyys avaavat Kailaan me- 
renkulkijoille usein kosmisia näköaloja. Heidän päämäärästään tiedoton purjehtimisensa on kuin Martinsonin "Aniaran" avaruuslaivan ikuista matkantekoa tyhjyydessä. Purjehtiminen ei koskaan pääty mihinkään satamaan. Vain kuolema voi olla matkan määränpää. Maa - taivas vastakohta sulkee Kailaan runoissa piiriinsä koko avaruuden. "Vaeltajan oodissa" on matkamiehen silmien eteen levitetty huikaisevia näköaloja:

Kaukaisuuden tuon, mikä silmään siintää, maiden ääret, myös arot valtamerten, taivaan tähti-tunturit - kaiken mielit luonasi nähdä.

"Katseessa" meren ja taivaan yhtyminen mahtuu yhteen ainoaan silmäpariin. Korkeus ja syvyys avaavat runossa äärettömiä näköaloja, joista Kailaan dualismi selvästi piirtyy lukijan ulottuville. Katsemerestä nousee koralleja, kultahiekkaa, mutta kuva vaihtuu hetkessä: sielun pohjalta nousee himmeitä varjoja ja mustekalan kuvajainen. Runoilija nousee korkeuksiin kevyesti, kuin siivillä, mutta putoaa taas syvimpään syvyyteen, jossa on vain varjoelämää. "Kalypson vangissa" kevyesti taivaan sinessä kiitävät pilvet ovat vapauden symboleja, mutta ne tuntuvat olevan saavuttamattoman korkealla. Yksinäisellä saarella kohtaloaan kiroova mies muuttuu yhä pienemmäksi mahtavan avaruuden puristuksessa. "Hollantilaisessa". tähtitaivas kuvastuu mereen, ja sen kuvajainen saa runoilijassa heräämään tutun verkkokuvitelman: tähdet ovat meressä "kuin verkon silmukoissa tuhat kalaa". Taivas muistuttaa runossa aavelaivureita myös heidän syyllisyydestään, kuvitelma avartuu eettiselle tasolle. Jumalanpilkasta johtuvan syyllisyyden Hellaakoski ilmaisee luonteensa pakosta jyrkin sanoin: "Kakssataa vuotta, se muistakaa, / on kynnetty merta aukeaa, / kiro ankara yllämme, taivaan panna, / joka ei levon lohtua meille anna." Kailaan runossa ei syyllisyydentunne ole yhtä kovaa ja sovittamatonta. Hänen "unten-kalastajansa" rikkomus taivasta vastaan onkin lähinnä vain siinä, että hän tavoittelee ikuista kauneutta, jonka vain taivas voi lahjoittaa. Runossa "Laulu kotirannoista" on taas Kailaalle ominainen taivas-meri vastakohta, meri ja taivas kuvastuvat toisissaan: "Kreikan meri syvin taivaankuulloin laivaa kantaa." Huomattakoon tässä, että vastakohtaa vesi-taivas ei Kailaan runoudessa ole muualla 
kuin merikuvitelmissa. Virta, lampi, lähde eivät kuvasta taivasta itseensä. Niinpä runossa "Kuva" Narkissos, kuvan vanki, on niin uppoutunut omien kasvojensa ja oman sielunsa tuijottamiseen, että tuntuisi oudolta kuvitella hänen näkevän Runebergin tavoin pilvien kuvajaisia lähteen kalvossa.

Kailaalla on merirunoja eniten kokoelmassa Purjehtijat, jonka nimikin jo viittaa merellisiin maisemiin. Ilmestymisvuosi $1925 \mathrm{kan}$ nattaa tässä panna erikoisesti merkille. Ennen kokoelmansa julkituloa Kailas liikuskeli paljon nuorten modernistien parissa. Oman tärkeän merkityksensä hänen kohdallaan sai pääsy aikakauslehti Ultran ympärille kerääntyneeseen kirjalliseen ryhmittymään. Nuori radikaaliryhmä lauloi voimakkaassa ja rohkeassa ekspressionismissaan merestä dynaamisena olentona, joka virtasi elämän tyhjentymättömistä lähteistä. Tämän "avoimen" merisymboliikan rinnalla oli toinen, salatumpi, joka ennen kaikkea tähysteli meren syvyyksiä ja halusi tällä kuvata tummia, väkeviä ja salaperäisiä voimia ihmisen sisimmässä.14 Erikoisesti dynaaminen Diktonius toi lyriikassaan esiin alituisesti liikkeessä olevan meren. Myös proosatuotannossaan hän käyttää vesimaailmasta kuvia, jotka ovat luonteenomaisia hänelle ja koko ryhmälle: "Sök ej skönhet hos oss, sök ej sanning; filosofi, om i liv eller konst, tillhör historiens $1 \mathrm{u} g \mathrm{~g}$ vat t e n p e ri o d e r (harv. tässä); rasande framstörtande kan vi blott vara ärliga. Man kallar oss expressionister."15 Merkille pantavaa juuri tässä yhteydessä on, että Diktonius käänsi Sandburgin runon "Young sea", jonka hän sijoitti käännöskokoelmansa Ungt hav alkuun. Siinä oleva kuva merestä, joka ei koskaan ole hiljaa, sopi hyvin Diktoniuksen Iuonteenlaatuun. ${ }^{16}$ Myös Edith Södergranin runoja esiintyi usein Ultran palstoilla, ja hän sai Kailaasta kiihkeän ihailijan.17 Södergranin merirunous kumpusi syvältä sielun pohjasta, ja sille on usein ominaista runoilijan oman itsensä samastaminen mereen. Myöskin Kailaan eräs oma runo, "Atlantiksen" ensi versio pääsi Ultran sivuilla julkisuuteen.18 "Atlan-

14 Alf Kjellén, emt. s. 161.

15 Alf Kjellén, emt. s. 161. Ultra 8/1922. Olof Enckell, Den unge Diktoxius. Helsingfors 1946. S. 192.

16 Alf Kjellén, emt. s. 161.

17 Maunu Niinistö, emt. s. 108.

18 Maunu Niinistö, emt. s. 109. Ultra 5/1922. 
tiksessa" on mielikuva ihmisen sielusta, joka on pohjaton kuin meri, arvaamattomia intohimoja ja kuohuja täynnä. Ei liene oudoksuttavaa, että Kailaan lapsuudenaikaisia Raamatusta saatuja merikuvitelmia oli omiaan täydentämään pohjaton syvyyksiin pyrkiminen, jota suuntaa suomenruotsalaisten kirjailijoiden joukossa edusti jossakin määrin myös Jarl Hemmer.19 Se soveltui erinomaisesti myös Kailaan omaan lyyrikonlaatuun. Hänen luomishetkensä ei merkitse avartumista elämäntäyteiseen todellisuuteen, vaan pakoa ulkonaisesta sisäänpäin. ${ }^{20}$ "Liikkumattoman" merisymboliikan, syvyyteen tuijottamisen Kailas toi esiin myös lähdekuvassaan. Runossa "Kuva" ovat katselija ja kuva kuin kiinni toinen toisissaan, kytkettyinä toisiinsa ajasta aikaan:

Tuhannet vuodet hiljaa kahisten vaelsi pensastoissa tuulten lailla. Syvyyden kalvoon yhä katselen.

Kuvastimess' on siinä kuva vertaa vailla.

Kailaan henkisiä kaksoiskasvoja kuvaa hyvin se, että hän merisymboliikassaan on valinnut molemmat ulottuvuudet. "Vesiaavikot vapaat" ja "vyöryvät aallot" houkuttelevat häntä, mutta sisäistä tunnettaan ja runoilijalaatuaan seuraten län ei saata seurata niitä. Hänen on pakko pyrkiä "yhä syvemmä syvyyteen". Tarkiainen sanoo Runojen esipuheessa Kailaan runoilijapersoonallisuuden olevan "väkevän älyllisen intohimon leimaaman",21 ja saman toteavat eri yhteyksissä myös Koskenniemi ja Koskimies.22 Älyllisen laadun voimakkuus hänen persoonallisuudessaan tuo kiinnostuksen "syväluotaukseen" myös lyriikan merikuvitelmissa. Hän ei säiky sitä, että vertauskuvallisen sielumeren pohja on niljakas, "meri saita on saaliistaan", ja että löydöt tuskin ovat omiaan tekemään etsijää onnelliseksi: "mut pohjallas on varjot himmeät, / ui siellä mustekalan kuvajainen." Runoilija aavistaa jo tähystellessään meren pohjaan, että siellä on vain "peikkojen luolia". Vain taivaasta saattoi

19 Alf Kjellén, emt. s. 160.

20 Tatu Vaaskivi, Uuno Kailas. Valvoja-Aika 1935. S. 136.

21 V. Tarkiainen, esip. Uuno Kailaan Runoihin. 7. pain. Porvoo 1946. S. 7.

22 V. A. Koskenniemi, emt. s. 225. Rafael Koskimies, Uuno Kailas. Kirjallisia näköaloja. Helsinki 1936. s. 118. 
langeta kirkkautta meren pohjaan. Ylöspäin kurkottuu myös "Sielun" runoilija, joka makaa meren pohjassa vangittuna:

Minä kuoleman mereen hukuin.

Minä vaivuin syvyyteen

udun himmeän kaltaiseen

ja sen pohjalla sidottuna nukuin.

"Sielussa" ei enää ole "Verkossa"-runon kärsivää vaikerrusta. Siinä on pikemminkin tyyntä luottamusta vapahdukseen, "vaeltavaan veljeen, joka riippui ristillä" merenpohjaan kytketyn runohenkilön omassa ruumiissa. Runoilija tarkoittaa kärsimystä, joka asuu jokaisen ihmisen sisimmässä.

Kailaan ikäpolven runoudessa on merisymboliikkaa runsaasti varsinkin Sarkian ja Viljasen lyriikassa. Viljasella se merkitsee suoranaista lisää hänen maisemakuviinsa, Sarkialla taas unelma merestä on osa hänen kauneudenunelmaansa. Se on eräänlaista haltioitunutta yhtymistä luontoon, ihanaa vaipumista alkumeren syliin. Mutta se ei ole porautumista syvyyteen, symbolista ihmissielun arvoituksen etsimistä sen pohjasta. Kailaalla se on tuskallisempaa, tietoisempaa pyrkimystä selvyyteen kaiken uhalla. Se on kaipausta ja pelkoa samanaikaisesti, kuten runossa "Katse":

Oot arvoitusten meri, vailla rajaa.

Ain' uusin, avartuvin taivahin

ja uusin, toivottomin syvyyksin

sä houkuttelet syliis sukeltajaa.

Kun Uuno Kailaan kuolinsanoma saapui kaukaa Ranskan rivieralta, vertasi Koskenniemi muistosanoissaan runoilijaa Faethoniin, auringonjumalan ja Okeanoksen tyttären poikaan.23 Se huima retki, joka uskaliaalla Faethonilla päättyi taivaankannelta veden syvyyteen, toteutui myös Kailaan merirunoudessa.

Kerttu TANner: Das Meer in den Gedichten des finnischen Lyrikers Uuno Kailas

Uuno Kailas gab fünf Gedichtsammlungen heraus. Jeder Band enthält eine Anzahl Gedichte mit Meeresmotiven. Die meisten finden sich in dem Band

23 V. A. Koskenniemi, emt. s. 217. 
"Purjehtijat" (= die Segler), dessen Titel schon Zusammenhänge mit der See erkennen lässt. Da der Lyriker einen Sensus für die Natur kaum besass, und der Verfasser seiner Biographie, Dr. Niinistö, eine nahe Verbundenheit des Dichters mit der See als geographischer Erscheinung nicht nachweisen konnte, müssen wir vermuten, dass die Meeresmotive in seinen Gedichten grösstenteils der Literatur entstammen. Schon während seiner Schulzeit wurde er mit V. A. Koskenniemis und Eino Leinos Lyrik vertraut. Durch die mit dem Meer zusammenhängenden Motive dieser Dichter sind seine Vorstellungen von offenem, weitem Meer fruchtbringend angeregt worden; zumindest ist es möglich, in der Wahl der Motive zahlreiche Parallelen zu ziehen. Die Begeisterung des Dichters Kailas für die Lyrik Charles Baudelaires und vor allem für dessen Gedichte mit Meeresmotiven tritt auch in seiner eigenen Lyrik deutlich zutage. In der Gedichtsammlung "Silmästä silmään" veröffentlichte Kailas vier Baudelaire-Übersetzungen, von denen drei Meeresbilder aufweisen. Seine Dichtung trägt auch Spuren einer frühen Vertrautheit mit dem von der Bibel vermittelten Weltbild.

Tiefe ist die hervorragendste Eigenschaft der See in Kailas' Dichtung. Ihre Tiefendimension ist in vielen seiner Gedichte verlockender als die Erstreckung in die Weite, gegen den Horizont. Die oberen Wasserschichten sind beweglich, in stetem Wechsel begriffen - tief unter der Oberfläche aber gibt es ein merkwürdig fahles, unbewegliches Leben. Die Tiefenvorstellungen des Dichters fanden auch den Beifall der jungen Modernisten der 20er Jahre, unter denen er sich gern bewegte. Aus dieser Epoche stammt auch die exoiische Farbenfreude, die vor allem den Meeresgedichten aus der ersten Schaffensperiode des Dichters ihre Prägung verleiht.

Der Gegensatz von Himmel und Meer ist in Kailas' Dichtung ganz besonders wirkungsvoll. Er kommt in vielen seiner Gedichte pathetisch und bezwingend zum Ausdruck. Die schwindelnde Föhe der Himmelsglocke und die bodenlose Tiefe des Meeres eröffnen oftmals geradezu kosmische Aspekte. Höhe und Tiefe - dieser Gegensatz bringt auch die dualistischen Züge seiner Lyrikernatur ausdrucksvoll zum Vorschein. Auch darin zeigt sich sein geistiges Doppelgesicht, dass ihm die Oberflächengewässer, "die freien Wasserwüsten" und "die tosenden Wellen" Symbole der Freiheit und des schnellen Dahineilens sind, wogegen er selber genötigt ist, immer tiefer zu dringen, "immer tiefer in die Tiefe". Seine äusserst intellektuelle Art regt zu Betrachtungen auch seiner symbolischen Meeresvorstellungen an. Das Tauchen tief unter die Oberfläche ist für ihn gleich dem Eindringen in die verborgensten Winkel der Menschenseele, ein bewusstes Streben nach Klarheit allem zum Trotz, ein Fliehen des Oberflächlichen. 